\title{
Correction to: Study on the methodology of striae gravidarum severity evaluation
}

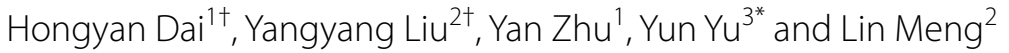

The original article can be found online at https://doi. org/10.1186/s12938-021-

00945-w.

${ }^{*}$ Correspondence:

lyy_03053@163.com

†Hongyan Dai and Yangyang

Liu contributed equally to

this work

${ }^{3}$ School of Bioengineering and Information, Nanjing

Medical University, Longmian

Avenue 101, Nanjing, Jiangsu,

China

Full list of author information is available at the end of the article

\section{Correction to: BioMed Eng OnLine (2021) 20:10 https://doi.org/10.1186/s12938-021-00945-w}

Following publication of the original article [1], the author noticed an error in the first affiliation. The unit name be "Xishan People's Hospital of Wuxi City, Dacheng Road 1128, Wuxi, Jiangsu, China" instead of "Yanshan People's Hospital of Wuxi City, Dacheng Road 1128, Wuxi, Jiangsu, China." This corrected affiliation appears in the following texts:

In Methods section, the first sentence should read, "Women were recruited from the Xishan People's Hospital of Wuxi City" instead of "Women were recruited from the Yanshan People's Hospital of Wuxi City".

In the same section, the fifth sentence should read, "The study was approved by the Xishan People's Hospital of Wuxi City Ethics Committee" instead of "The study was approved by the Yanshan People's Hospital of Wuxi City Ethics Committee".

Under Declarations, the first sentence in "Ethics approval and consent to participate" should be "This study was approved by the Xishan People's Hospital of Wuxi City Ethics Committee" instead of "This study was approved by the Yanshan People's Hospital of Wuxi City Ethics Committee".

The original article has been corrected.

\section{Author details}

${ }^{1}$ Xishan People's Hospital of Wuxi City, Dacheng Road 1128, Wuxi, Jiangsu, China. ${ }^{2}$ College of Information and Communication Engineering, Nanjing Institute of Technology, Hongjing Avenue 1, Nanjing, Jiangsu, China. ${ }^{3}$ School of Bioengineering and Information, Nanjing Medical University, Longmian Avenue 101, Nanjing, Jiangsu, China.

Published online: 17 December 2021

Reference

1. Dai H, Liu Y, Zhu Y, Yu Y, Meng L. Study on the methodology of striae gravidarum severity evaluation. BioMed Eng OnLine. 2021;20:10. https://doi.org/10.1186/s12938-021-00945-w.

Publisher's Note

Springer Nature remains neutral with regard to jurisdictional claims in published maps and institutional affiliations. author(s) and the source, provide a link to the Creative Commons licence, and indicate if changes were made. The images or other third party material in this article are included in the article's Creative Commons licence, unless indicated otherwise in a credit line to the material. If material is not included in the article's Creative Commons licence and your intended use is not permitted by statutory regulation or exceeds the permitted use, you will need to obtain permission directly from the copyright holder. To view a copy of this licence, visit http:// creativecommons.org/licenses/by/4.0/. The Creative Commons Public Domain Dedication waiver (http://creativecommons.org/publicdomain/zero/1.0/) applies to the data made available in this article, unless otherwise stated in a credit line to the data. 